\title{
LAMELIBRÂNQUIOS TRIÁSSICOS DE RIO CLARO (ESTADO DE SÃO PAULO)
}

\author{
Josué Camargo Mendes
}

\section{R E S U M O}

No presente trabalho o autor estuda uma coleção de lamelibrânquios triássicos da série Corumbataí por êle próprio organizada no Município de Rio Claro, Estado de São Paulo.

Coleções menores da mesma região foram versadas por K. Holdhaus (1918) e C. Reed (1932).

O bom estado geral de conservação dos espécimes da atual coleção tornou possivel a observação de particularidades morfológicas e a discussão dos valores sistemáticos anteriormente conferidos.

São propostos dois novos gêneros, Jacquesia e Pinzonellopis, para formas referidas antes por Reed, respectivamente, aos gêneros Myophoriopis Whörmann e Pachycardia Hauer e descritas quatro novas espécies: Pseudocorbula camaquensis, P. triangularis, Anodontophora intricans e Pinzonella trigona.

O total das espécies registradas é de 16 (Reed registrou um total de 9), distribuidas por 2 horizontes faunística e litológicamente distintos.

Duas das conchas referidas por Reed, Pachycardia neotropica e Myophoriopis cf. carinata, não foran verificadas pelo autor.

Com 'exceção das 4 entidades novas e duma forma não determinada especificamente, as demais constituem espécies já assinaladas nêsse ou em outros pontos do triássico do Sul do Brasil.

A malacofauna dos dois horizontes fossiliferos estudados, é identica às triássicas conhecidas de outras localidades do Sul do Brasil, bem como do Uruguai e Paraguai.

Quanto ao valor cronológico da associação, parece que as 'evidências continuam favorecendo a idade triássica superior, proposta por Reed, apesar das alterações sistemáticas aquí introduzidas. Só estudos futuros, entretanto, poderão fornecer elementos mais seguros para uma avaliação satisfatória. 


\section{S U M M A R Y}

The present paper is the study of a collection of Triassic shells in the Corumbatahy Series made by the author in the municipal district of Rio Claro in the State of São Paulo.

Smaller collections made in the gaine region have been studied by K. Holdhaus (1918) and F. R. Cowper Reed (1932).

The exceptionally fine preservation of the material in this collection has permitted a reconsideration regarding morphological details and of systematic values.

Two new genera have been proposed, viz.: Jacquesia and Pinzonellopis, for the forms formerly referred to by Reed as Myophoriopis Whörmann and Pachycardia Hauer, respectivelly, and four new species have been described: Pseudocorbula camaquensis, P. triangularis, Anodontophora intricans and Pinzonella trigona.

The total number of species amounts to 16 (Reed registered a total of 9), distributed in two faunistic horizons, lithologically distinct.

Two of the shells referred to by Reed: Pachycardia neotropica and Myophoriopis cf. carinata, have not been verified by the author.

With the exception of the four new species, and one of the forms not identified specifically, the remaining forms have already been assigned to this or other points of the Triassic of southern Brazil.

Regarding the age of the fauna, the evidence continues to favour assignment to the Upper Triassic as proposed by Reed, in spite of the systematic alterations here suggested. Future studies will furnish elements for a more satisfactory conclusion.

\section{N T R O D U Ç $\tilde{A} O$}

Há muito que a literatura geológica menciona a ocorrência de horizontes com lamelibrânquios fósseis na série Corumbatai do Estado de S. Paulo. Sob o ponto de vista paleontológico, entretanto, essa malacofauna é escassamente conhecida e só foi versada até agora em dois pequenos trabalhos.

No primeiro (8), uma memória da autoria do prof. IInldhaus, datada de 1918, foram estudados alguns espécimes procedentes do Morro da Mata Negra, situada cêrca de 19 quilômetros da cidade de Rio Claro. Propôs-se para os mesmos o novo gênero Plesiocyprinella, conferindo-se o nome de $P$. carinata à única espécie revelada.

O segundo trabalho $(15 ; 15 \mathrm{a})$, devido a $\mathrm{C}$. Reed, de data muito mais recente, versou uma pequena coleção de conchas 


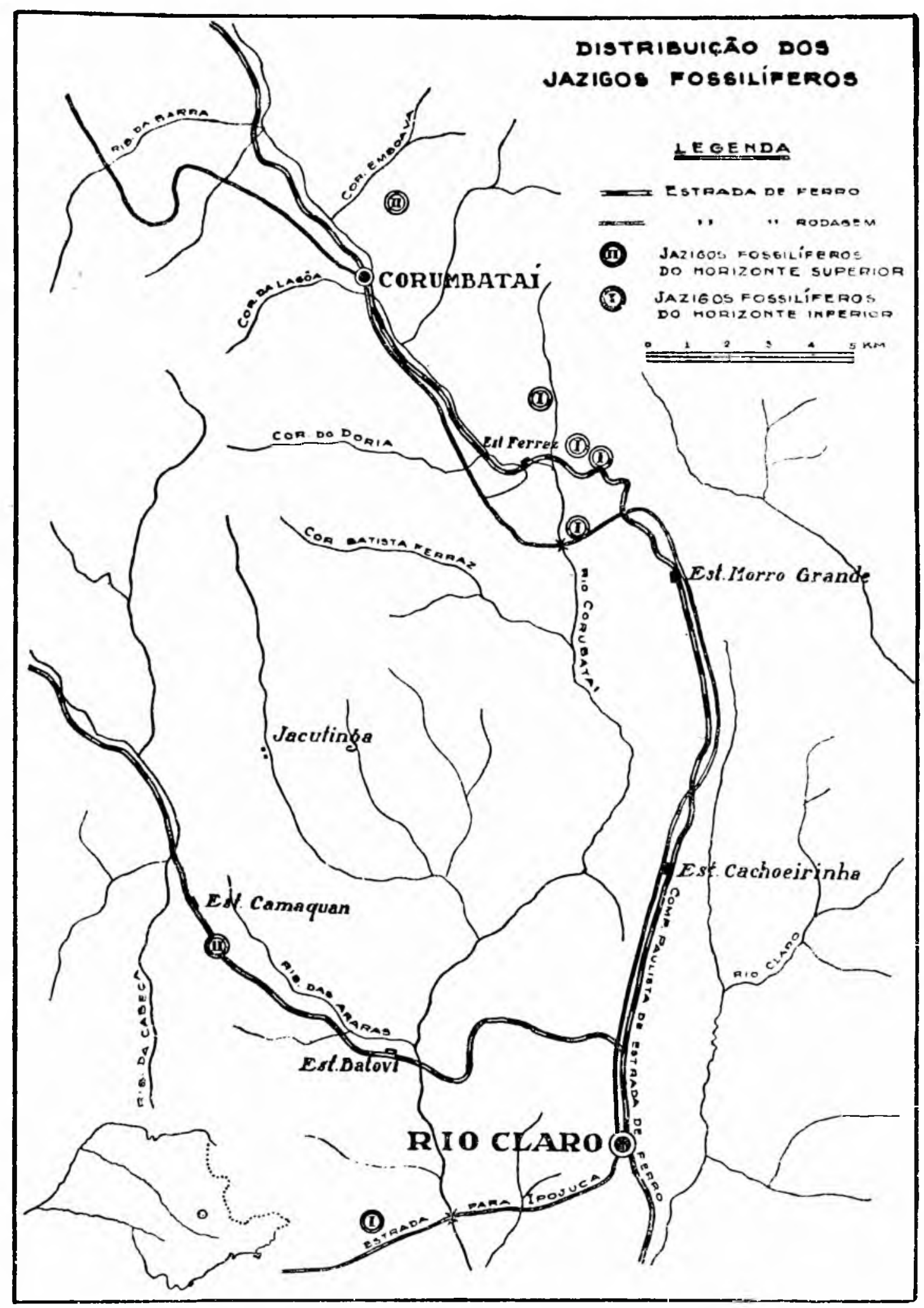


efetuada pelo Barão von Huene no Município de Rio Claro, entre Morro Grande e Ferraz e em Camaquan. Partindo dêsse material foram propostos dois novos gêneros, Ferrazia e Pinzonella, reconhecendo-se outros espécimes como formas já referidas ao triássico sul-americano. A lista das espécies então registradas é a seguinte $(15, \mathrm{p} .479-480)$ :

Ferrazia cardinalis gen. e sp.n.

Pinzonella illusa gen. e sp.n.

Pinzonella similis sp.n.

Myophoriopis brasiliensis Reed

Myophoriopis ef. carinata Bit.

Plesiocyprinella carinata Hold.

Pachycardia neotropica Reed

Pachycardia rugosa var. occidentalis Reed Anodontophora sp.

Teve êsse trabalho o grande mérito de confirmar as suposições de se tratar duma fauna análoga à revelada anteriormente no triássico do Estado do Paraná $(13 ; 13 a)$.

O presente trabalho é o relato dos resultados a que cheguei, estudando uma coleção de lamelibrânquios maior, por mim organizada no mesmo Município de Rio Claro (Estado de S. Paulo). No curso das pesquisas procurei sempre prestar o máximo possivel de atenção à estratigrafia local a fim de tornar segura a referência dos espécimes aos respectivos horizontes. O material forneceu espécies desconhecidas para o triássico sul-americano e, dado o seu bom estado geral de conservação, possibilitou, não raras vezes, a observação de particularidades morfológicas e a discussão dos valores sistemáticos anteriormente conferidos.

\section{OS D O IS HORIZONTES COM} L. A M E L I B R Â N Q U I O S

Estudando o perfil geológico entre Morro Grande e Ferraz e entre Batovi e Itirapina, von Huene (9) verificou a ocorrência de dois bancos de marga com lamelibrânquios, intercalados na sucessão de folhelhos variegádos da série Corumbatai. Reconheceu as conchas como Megalodon?, Myophoria e formas parecidas com Myophoria e presumiu tratar-se do mesmo horizonte fossilífero de Rio Claro (Paraná), revelado por Du 'Toit (6) e estudado faunísticamente por Reed $(13 ; 13 a)$.

O banco fossilífero mais profundo apresentava-se cortado por diques diabásio e as circunstâncias poderiam, de certo modo sugerir uma perturbação local, devida à intrusão da eruptiva. Von Huene, entretanto, regeitou tal hipótese, porque as camadas subjacentes não correspondiam litológicamente ai às do outro horizonte. 


\section{SECÇÃO I \\ IKm.5 aquem da Estação de Camaquan}

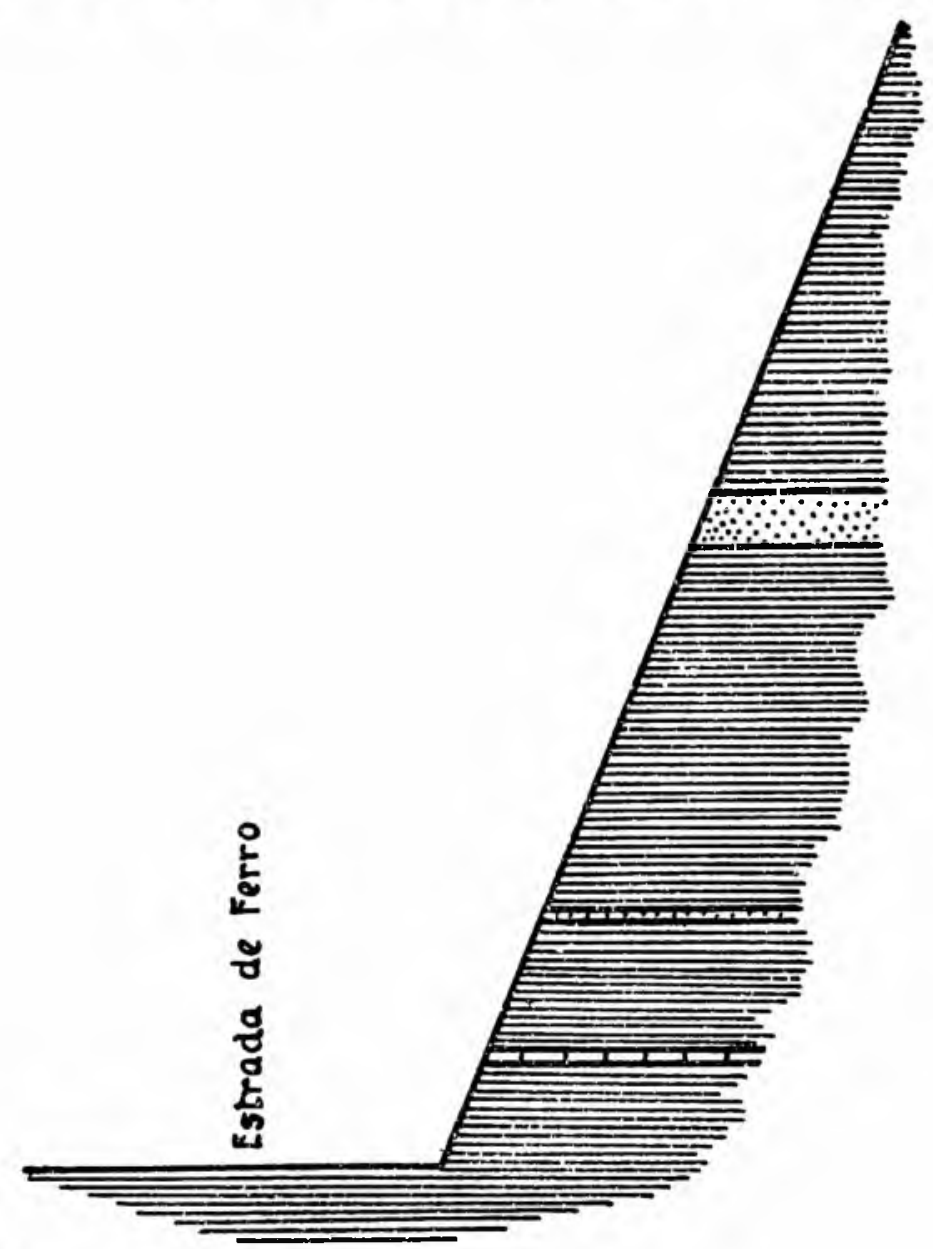

Arenits

folhelhos variegados

Marga fosoilifera

(Worizonte superior)

Q.e. P. P. Gompelare

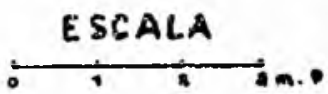


A pequena coleção organizada por von Huene foi mais tarde estudada por Reed $(15 ; 15 a)$. Neste trabalho referiram-se os dois horizontes como o "horizonte superior" e o "horizonte inferior" do dr. von Huene.

A malacofauna do horizonte inferior (Morro GrandeFerraz) forneceu as seguintes espécies $(15$, p. 479):

Ferrazia cardinalis gen. e sp.n.

Pinzonella illusa gen. e sp.n.

Pinzonella similis sp.n.

Myophoriopis brasiliensis Reed

M. cf. carinata Bit.

Plesiocyprinella carinata Holdhaus

A malacofauna do horizonte superior (Camaquan) revelou (idem, idem) :

$P$. neotropica Reed

Pachycardia rugosa Hauer, var. occidentalis Reed Anodontophora sp.

Efetivamente as minhas observações no Município de Rio Claro permitiram verificar a ocorrência de dois horizontes com lamelibrânquios litológica e faunísticamente distintos.

Constitue o horizonte superior uma camada de marga de côr creme, ricamente fossilifera, com espessura variante entre 10 e $15 \mathrm{~cm}$. Reconheci êste horizonte próximo à estação de Camaquan (vide carta da distribuição dos jazigos), possivelmente no mesmo local visitado por von Huene, e em Corumbataí. Na primeira localidade (vide Secção I), a camada fossilifera é cortada pela estrada de ferro cêrca de 1 quilômetro e meio antes da estação e está a uma altitude de, aproximadamente, 610 metros (altitude da Estação de Camaquan $=634 \mathrm{~m}$.). Sobrepõ̃em-se-lhe localmente cêrca de 80 metros de folhelhos argilosos avermelhados. Em Corumbataí o leito fossilífero aflora aproximadamente à mesma altitude na chácara do sr. João Raven. O jazigo dista cêrca de 2 quilômetros da estação.

O horizonte inferior é de arenito pardo-avermelhado e apresenta uma espessura média de cêrca de $25 \mathrm{~cm}$. Examinei afloramentos dêste horizonte nas seguintes localidades: chácara Santa Elisa, cêrca de 6 quilômetros a W da cidade de Rio Claro; à direita da estrada de rodagem Rio ClaroCorumbatai, alguns metros antes da ponte sòbre o rio Corumbataí; chácara do sr. Göss, pouco mais de 1 quilômetro antes da estação de Ferraz e à direita da linha férrea (vide Secção II) ; cếrca de 1 quilômetro e meio ainda aquém dessa estação, onde a camada é cortada pela estrada de ferro; chácara dos irmãos Culik, mais ou menos a dois quilôme- 
tros a NE dessa mesma estação. A altitude verificada por mim para êste horizonte nas localidades referidas é aproximadamente de $575 \mathrm{~m}$.

Há portanto cêrca de 35 metros de folhelhos intercalados entre os dois horizontes.

O horizonte inferior é menos rico em fósseis que o superior e os espécimes nêle contidos mostram, em geral, uma côr rósea caracteristica.

A lista das espécies cuja ocorrência foi por mim verificada nos horizontes acima referidos é a seguinte:

Horizonte superior :

Pinzonellopis occidentalis (Reed)

Jacquesia brasiliensis (Reed)

Pseudocorbula subtriangularis Reed

$P$. anceps Reed

$P$. camaquensis sp.n.

$P$. triangularis sp.n.

Anoplophora intricans sp.n.

Myoconcha sp.

Horizonte inferior:

Pinzonella illusa Reed

P. similis Reed

$P$. trigona sp.n.

Plesiocyprinella carinata Hold.

Terraia altissima (Hold.)

Pleurophorus cf. elongatus Moore

Ferrazia cardinalis Reed

Pleuromya aff. mactroides Schloth.

Nos jazigos estudados, as espécies numéricamente mais freqüentes sã̃o, no horizonte superior, Pinzonellopis occidentalis (Reed) (Pachycardia rugosa var. occidentalis Reed) e, no horizonte inferior, Pinzonella similis Reed.

\section{E S C R I Ç Ã O D A S E S P ÉC I E S}

\section{A) Horizonte inferior}

\section{GENERO PINZONELLA REED 1932}

O gênero Pinzonella foi proposto por Reed, em 1932 (15, p. 482-484; 15a, p. 28-31) para alguns dos espécimes colhidos por von Huene entre Morro Grande e Ferraz (São Paulo). Foram então descritas dentre os mesmos duas espécies: $P$. illusa e $P$. similis. 
Posteriormente $(16 ; 16 a)$, Reed assinalou a ocorrência de $P$. similis em Rio Claro, Municipio de Canoinhas, Estado de Santa Catarina, referindo, no mesmo trabalho, exemplares de uma localidade situada entre San José e Valenzuele, Paraguai, enviados pelo falecido prof. Windhausen em 1929, como $P$. cf. illusa. Foi assinalado o gênero também no Estado do Paraná ao longo do ramal Riosinho-Guarapuava pelos paleontólogos da Divisão de Geologia $(17$, p. 57).

o gênero tem, pois, larga distribuição no triássico sulamericano. No presente trabalho descreve-se uma terceira espécie - P. trigona.

Julgo fraca a semelhança estabelecida por Reed entre êste gênero e Pachycardia Hauer (15, p. 483), pois distinguem-se, fácilmente, tanto pelos caracteres externos como pela charneira. Pinzonella liga-se estreitamente ao novo gênero Pinzonellopis proposto no presente trabalho e descrito mais adiante.

\section{Pinzonella trigona sp.n.}

Est. I, figs. 1, 2a, $2 b$.

Material: 7 valvas direitas e 1 individuo completo. Estado: todos os indivíduos estão bem conservados, mas só o de n. VII mostra os caracteres internos.

Medidas :

\begin{tabular}{|c|c|c|}
\hline $\begin{array}{l}N^{\circ} \text { I } \\
N^{0} \text { (valva dir.) } \\
\text { (completo) }\end{array}$ & c ${ }_{14.5} 11 \mathrm{~mm} 5$ & a $8 \mathrm{~mm} 5$ \\
\hline N. VI (valva dir.) & 19,5 & 16 \\
\hline
\end{tabular}

Procedência: os indivíduos de ns. VII e VIII procedem do jazigo à direita da estrada de rodagem Rio Claro-Corumbatai; os restantes procedem da chácara do sr. Göss, Ferraz.

\section{Descrição}

Concha subtriangular, ineqüilatera, ligeiramente ineqüivalva, pouco entumecida, deprimida lateralmente. Umbo proeminente, anterior e fortemente prosógiro. Extremidade posterior truncada verticalmente; extremidade anterior convexa. Carena posterior encurvada, indo do ápice do umbo até à extremidade inferior da truncatura posterior. Lúnula lanceolada, profunda. Vulva pouco perceptível. A linha da carena e o bordo vulvar delimitam uma área triangular encurvada, percorrida medianamente por um sulco raso. Bordo inferior aproximadamente reto; bordo pós-umbonal obliquo, levemente convexo; bordo pré-umbonal côncavo e cur- 
to. Superfície externa ornada com estrias subconcêntricas mais ou menos pronunciadas. Ligamento opistodético.

Valva direita com a placa da charneira semi-circular apresentando uma fosseta dentária profunda e um dente anterior forte, subtriangular. A fosseta é triangular e tem o ápice voltado para a frente e ligeiramente para cima. Impressão do músculo adutor anterior subtriangular, profunda, localizada sob o dente anterior, quase confinante com o bordo anterior da valva. Não são perceptíveis nem a impressão do outro adutor nem a linha palial. Desconhecem-se os caracteres internos da valva esquerda.

Os exemplares mostram variação em altura (a percentagem da altura tomada sôbre o comprimento vai de 71 a $82 \%$ nos exemplares presentes).

No indivíduo completo pode-se observar que a valva esquerda é ligeiramente maior que a direita, recobrindo-a posteriormente por uma projeção do bordo dorsal.

\section{Discussão}

Os caracteres da concha descrita permitem referi-la ao gênero Pinzonella Re'ed. Pelo seu traçado subtriangular distingue-se bem das duas espécies até agora conhecidas dêsse gênero - $P$. illusa e $P$. similis, podendo ser referida como uma espécie nova.

Pinzonella illusa Reed

Material: 5 valvas esquerdas.

Estado: os exemplares acham-se em bom estado de conservação, mas nenhum dêles mostra Medidas: os caracteres internos.

$$
\begin{aligned}
& \text { N. }{ }^{\circ} \text { II c } 12 \mathrm{~mm} 5 \text { a } 11 \mathrm{~mm} 5 \\
& \begin{array}{llll}
\mathrm{N}^{\circ}{ }^{\circ} & \mathrm{V} & 17 & 15
\end{array}
\end{aligned}
$$

Procedência: o indivíduo $\mathrm{n}$. I procede da chácara Santa Elisa; os demais foram coletados na chácara do sr. Göss, Ferraz.

Embora os exemplares não mostrem os caracteres internos, tanto pelo aspecto externo como pelas medidas concordam perfeitamente com $P$. illusa Reed $(15$, p. $482-483$ t.19 f.6-11).

Pinzonella similis Reed

Est. I, fig. 3.

Material: algumas dezenas de individuos, muitos dos quais completos. 
Estado: a maioria acha-se em bom estado de conservação; o material inclue uma valva direita e uma esquerda que mostra satisfatóMedidas : riamente os caracteres internos.

$\begin{array}{llll}\text { N. } & \text { XV (completo) c } 12 \mathrm{~mm} 5 & \text { a } 9 \mathrm{~mm} 5 & \text { e } 6 \mathrm{~mm} 5 \\ \text { N. } & \text { LX (valva esq.) } & 19,5 & 15\end{array}$

Procedência: de tôdos os jazigos referidos do horizonte inferior.

Os espécimes sôbre os quais repousa a descrição original de $P$. similis $(15, \mathrm{p} .484 \mathrm{t} .19 \mathrm{f} .12,12 \mathrm{a})$ não permitiram a observação dos caracteres internos da valva direita. Por isso julgo de interêsse referí-los aquí, tomando por base o presente material.

A charneira da valva direita não difere essencialmente das apresentadas por $P$. illusa e $P$. trigona. $O$ seu confronto mais minucioso com a da segunda espécie não foi possível porque, infelizmente, os cinco indivíduos, que possuo, referíveis a $P$. illıs a não o permitem e a descrição de Reed, por muito fiel que seja, não é suficiente. Em relação a $P$. trigona tendo por base o confronto entre dois exemplares, apresenta a impressão do adutor anterior ligeiramente maior, o dente cardinal anterior mais robusto e a linha da charneira um pouco mais espêssa na região cardinal, atráz da fosseta dentária.

Os indivíduos completos permitem observar que, à semelhança de $P$. trigona, a valva esquerda é mais alta e recobre, posteriormente, a valva contrária pelo seu bordo dorsal. Esse traço parece ser, ademais, peculiar ao gênero.

\section{GENERO TERRAIA COX 1934}

Holdhaus descreveu 4 espécies novas de lamelibrânquios do Sul do Brasil referindo-as ao gênero Solenomor pha Cock (8, p. 4-15, 1 t. f 1-11): $S$. similis, $S$. intermedia, $S$. altissima e $S$. deflexa. Segundo Beder (2) o dr. Keidel identificou conchas das proximidades de Vila Rica (Paraguai) com pertencentes ao mesmo gênero Solenomorpha, provávelmente $S$. similis e $S$. intermedia Holdhaus.

Três das Solenomorpha de Holdhaus foram referidas na monografia de Reed sôbre o triássico do Sul do Brasil como Cuspidaria similis (Hold.) 14, p.44-46 t.4 f.1-5), Cuspidaria? deflexa (Hold.) (idem, p. 46) e Myophoria (Heminajas)? intermedia (Hold.) (ibidem, p.30 t.2 f.16).

Cox, estudando conchas procedentes do Uruguai, propôs para uma forma identificada como $S$. altissima de Holdhaus um gênero novo, que denominou Terraia $(4,269-273$ t.10 f.1a-c,2a-c, 4,5;4a, p.41-45). Em vista da grande variação notada nos seus exemplares referiu à mesma espécie 
$S$. intermedia Holdhaus; baseando-se na semelhança dos caracteres externos incorporou ainda na mesma espécie a forma descrita por Reed (14) como Isocyprina reducta.

Segundo Cox, o gênero Terraia parece ser aparentado com Pseudocorbula Philippi. Diferiria principalmente pela ausência de um dente cardinal anterior distinto na valva esquerda, cujo lugar é tomado pela projeção angular do bordo lunular.

\section{Terraia altissima (Holdhaus)}

Solenomorpha altissima Holdhaus 1919 (8, p.12-13 t.1 f.8-10) Isocyprina reducta Reed 1929 (14, p.40-42 t.1 f.11-17)

Material: 8 valvas direitas, 9 valvas esquerdas e um indivíduo completo.

Estado: 12 individuos em bom estado de conservação; o de número VI mostra satisfatóriamente os caracteres internos da valva direita; o indivíduo $n$. XIII é incompleto, mas Medidas: mostra bem a charneira da valva esquerda.

$$
\begin{aligned}
& \text { N. }{ }^{\circ} \text { II (valva direita) c } 15 \mathrm{~mm} \text { a } 11 \mathrm{~mm} 5 \\
& \mathrm{~N}^{\circ} \mathrm{X} \text { (valva direita) } 26 \quad 18,5
\end{aligned}
$$

Procedência: o indivíduo $n$. I procede da chácara Santa Elisa (Campo do Coxo); os de número II a XII procedem da chácara do sr. Göss, Ferraz; e o de n. XIII procede do jazigo à direita da estrada de rodagem Rio Claro-Corumbatai, próximo à ponte sôbre o Rio Corumbataí.

Mau grado o maior tamanho de alguns, os meus exemplares (formas adultas possivelmente) correspondem bem à Terraia altissima (Holdhaus) e a charneira, como é mostrado pelos indivíduos de ns. VI e XIII, concorda com a descrição de Cox.

Como já se disse antes, Cox propôs para Solenomorpha altissima Holdhaus um novo gênero, que denominou Terraia (4). Segundo aquêle autor, a variação notada nos exemplares por êle estudados permitiria referir à mesma espécie a forma descrita por Holdhaus como Solenomorpha intermedia, pelo menos a apresentada na figura $7 \mathrm{da}$ sua memória (8). Baseando-se na semelhança dos caracteres externos referiu tambem à mesma espécie a forma descrita por Reed (14) como Isocyprina reducta.

Efetivamente os meus exemplares mostram uma variacão no traçado. A percentagem da altura tomada sôbre o comprimento vai de $74-83 \%$. Mas a variação no material que estudei não permite ainda abalisar a sinonímia de $S$. intermedia Holdhaus (como figurada em 7 na memória de 
Holdhaus) estabelecida por Cox. S. intermedia (8, p:11-12 t.1 f.6-7) é fortemente alongada e trapezoidal, enquanto $T$ altissima é curta e triangular. A argumentação baseada no simples aspecto externo é frágil e nesse particular poderse-ia apontar também certa semelhança entre $S$. intermedia e Sanguinolites elongatus Holdhaus (8, p.16-19 t.1 f.13). Parece ser mais rasoável a sinonímização de $I$. reducta Reed. Não coincidem, é verdade, os caracteres dentários, mas Reed os descreveu baseado em moldes.

\section{GÊNERO PLESIOCYPRINELLA HOLDHAUS 1918}

$O$ gênero foi proposto por Holdhaus $(8$, p.20-23) para uma forma procedente do Morro da Mata Negra, cêrca de 19 quilômetros da cidade de Rio Claro que denominou $P$. carinata (idem, p.21-23 t.2 f.1-5). Os seus colecionadores foram Derby e Fenn. Reed refere a mesma espécie duma localidade situada entre Morro Grande e Ferraz, Município de Rio Claro, S. Paulo (15, p.485-486 t.19 f.13), onde foi coletada pelo Barão von Huene. O mesmo autor registrou-a também numa coleção procedente de Rio Claro, Paraná (14, p.76-78).

Holdhaus salientou a estreita ligação entre Plesiocyprinella e Plesiocyprina Munier Chalmas. Difeririam, segundo, êsse autor, sobretudo no que diz respeito às minúcias da charneira, aproximando-se pelo aspecto externo e por certos caracteres internos como a posição das impressões musculares.

Discutindo a idade do gênero, o prof. Holdhaus escreve que a semelhança do mesmo com o gênero jurássico Plesiocyprina não constitui elemento decisivo a respeito, posto que lamelibrânquios de aspecto externo muito aproximado e relacionados, talvez, até filogeneticamente com Plesiocyprina ocorrem em camadas de idade paleozóica superior. Nesse comentário possivelmente foi influenciado pela idade carbonífera que êle próprio atribuiu às formas associadas. A ligação apontada parece ter-se tornado sobremodo significativa, depois que Reed referiu a mesma associação ao triássico superior.

Contudo Reed manifestou-se a respeito $(14$, p.78), confessando-se incapaz de oferecer qualquer comentário de valor sôbre a concha, uma vez que a mesma lembrava simultâneamente formas pertencentes a gêneros diversos como Cypricardia rostrata Sowerby, exemplares imperfeitos de Myophoriocardium e espécies de Megalodon.

\section{Plesiocyprinella carinata Holdhaus}

Material: vários exemplares.

Estado: muitos individuos se acham em bom esta- 
Medidas:

do de conservação, mostrando alguns os caracteres da charneira.

$$
\begin{array}{cc}
\text { c }{ }_{43 \mathrm{~mm}} & \text { a } 13 \mathrm{~mm} 5 \\
& \\
438 \mathrm{~mm}
\end{array}
$$

Procedência: de tôdos os jazigos pesquisados, do horizonte inferior, mas o maior número de individuos foram coletados na chácara do sr. Göss, Ferraz.

A coleção inclui dois individuos com as valvas unidas, mạs infelizmente não completas.

Alguns exemplares apresentam-se deformados por compressão.

A descrição original da espécie apresentada dispensa aquí qualquer insistência a respeito.

\section{GENUS PLEUROPHORUS KING 1848}

\section{Pleurophorus cf. elongatus Moore}

Est. I, fig. 4

Pleurophorus cf. elongatus (Moore) Reed 1935 (16;16a, p.14) Sanguinolites elongatus Holdhaus $1918(9, \mathrm{p} .16-19$ t.1 f.13)

Material: 6 valvas direitas.

Estado: só o exemplar n. I está completo e mostra a charneira; os 4 restantes são incompletos e não mostram os caracteres internos.

Medidas (tomadas sobre o exemplar completo):

$$
\text { N. }{ }^{\circ} \text { I c } 26 \mathrm{~mm} 5 \text { a } 13 \mathrm{~mm} 5
$$

Procedência: Ferráz, chácara do sr. Göss.

As valvas são referiveis à espécie procedênte do Paraná descrita por Holdhaus como Sanguinolites elongatus (8, p.16-19 t.1 f.13). Concordam bem os caracteres externos. O material estudado por 'esse autor não revelou os caracteres internos e o seu melhor exemplar tinha a extremidade anterior obstruida. O maior espécime da minha colecão (n. I) possue dimensões ligeiramiente menores que as do figurado por Holdhaus. A sua parte anterior é estreitada, unindo-se o bordo inferior, convexo, em curva curta, ao bordo lunular, reto e inclinado, de modo a formar um angulo proeminente.

Em monografia datada de 1929 Reed sugeriu $(14$, p.78) que essa espécie poderia ser comparada com Pleurophorus elongatus Moore. Em trabalho ulterior $(16 ; 16 a, p .14)$ atribuiu um molde imperfeito de valva esquerda, procedênte de Canoinhas, Rin Claro (Estado do Paraná), a Pleurophorus 


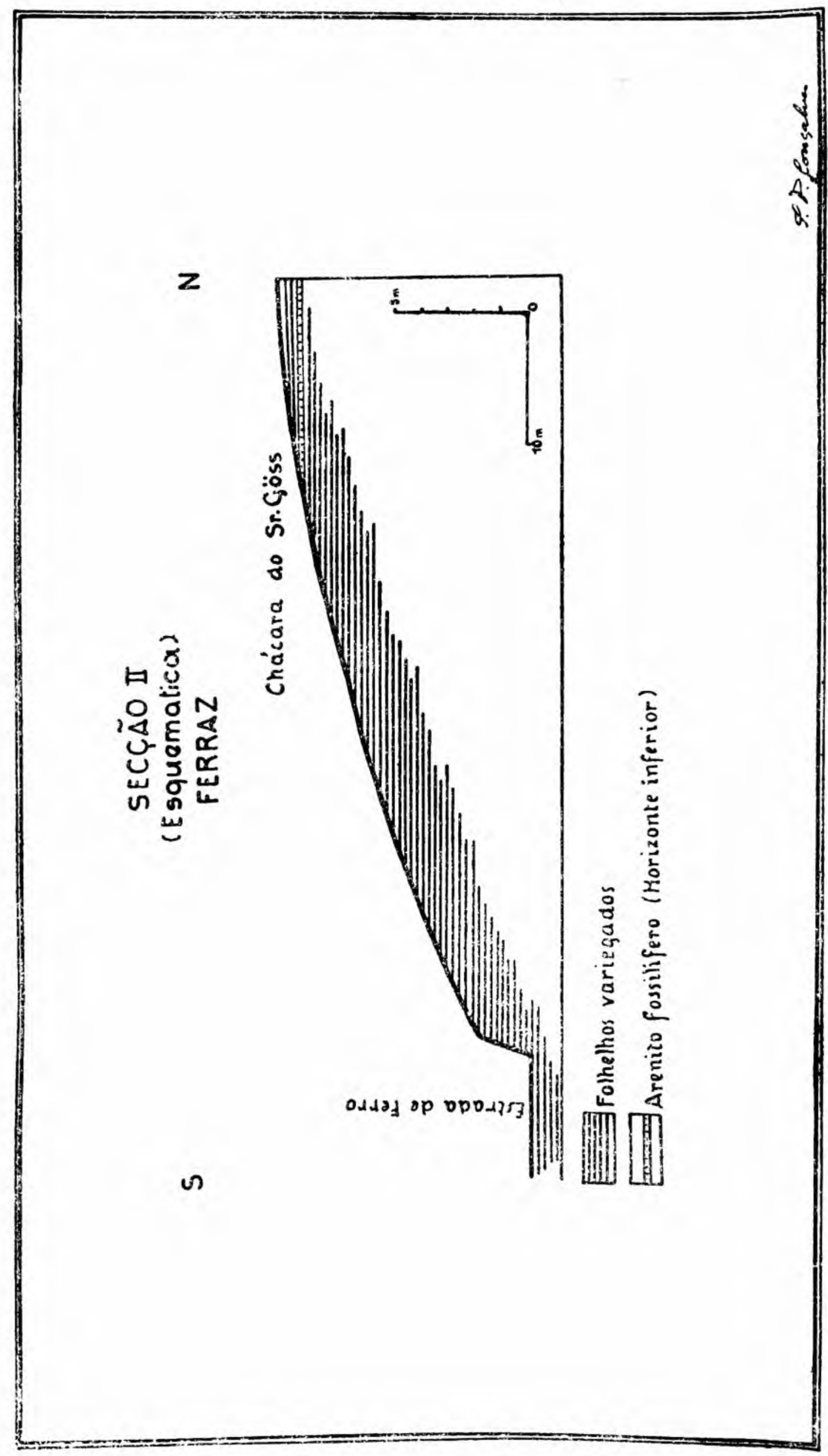


cf. elongatus (Moore). Fez notar tambem certa semelhança entre o seu exemplar e a concha do calcáreo com Myophoria de Huiairas (Perú) referida por Jaworski como Anodontophora? elongata Moore (10, p.122-124 t.4 f.8).

$\mathrm{O}$ individuo $\mathrm{n}$. I da minha coleção mostra os caracteres da charneira, aliás em não muito bom estado de conservação. A linha cardinal é sinuosa e apresenta uma saliência laminar que se inicia imediatamente sob o ápice umbonal, e prolonga-se até cêrca de $1 / 3$ do comprimento do bordo vulvar. A lunula e a vulva são estreitas e profundas. O ligamento é opistodético.

Parece-me frágil, no caso, qualquer argumentação de ordem sistemática decisiva baseada em caracteres duma charneira mal conservada.

Efetivamente, a julgar pelo aspécto externo, a espécie que Holdhaus denominou Sanguinolites elongatus assemelha-se à Pleurophorus elongatus Moore $(11$, p.503-504 t.XV f.14-15). Pelo aspecto externo lembra ainda Pleuromya elongata Schloth. (5, p.47 t.III f.2). A unica charneira, em não muito bom estado aliás, como já se disse, recorda a de Pleurophorus curionii Hauer (idem, p.40 t.IX f.7) do cárnico médio da Alemanha. Não vejo, porem, nenhuma semelhança notavel entre a forma presente e a de Huairas referida por Jaworski como Anodontophora? elongata.

Pleurophorus King viveu do devoniano ao triássico, tendo sido especialmente abundante no permiano.

Não se negaria que, simplesmente pelos caracteres externos, esta forma sugere o gênero Sanguinolites Mc Coy do carbonífero. Mas a sua charneira não é edentelosa e nem apresenta o bordo cardinal espessado ao longo de todo o seu comprimento como é proprio desse gênero $(7, \mathrm{p} .1175)$.

\section{GENERO FERRAZIA REED 1932}

O gênero foi criado por Reed (15, p.480-482 t.19 f.1-5; 15a, p.26-28 t.f.1-5) para conchas coletadas por von Huene nas proximidades de Ferraz (Municipio de Rio Claro, S. Paulo).

Foi então conferido o nome de Ferrazia cardinalis ao genótipo. Segundo o próprio Reed, recorda essa forma pelo aspecto externo tanto Myophoria kefersteini, como $M$. harpa de Münster, divergindo porém consideravelmente os caracteres da charneira.

$F$. cardinalis foi atribuida ao horizonte inferior. O gênero foi assinalado também no Estado do Paraná ao longo do ramal Riosinho-Guarapuava $(17, \mathrm{p} .57)$. 


\section{Ferrazia cardinalis Reed}

Material: as valvas são incompletas; únicamente uma delas mostra a charneira, mas em mau estado.

Procedência: Ferraz, chácara do sr. Göss.

As conchas em questão concordam bem com a espécie, descrita por Reed $(15$, p. $480-482$ t.19 f $1-5 ; 15 a$, p.26-28 t. f.1-5), da mesma região.

Devo acrescentar que se trata duma forma não muito frequente, pelo menos nas localidades por mim pesquisadas.

\section{GENERO PLEUROMYA AGASSIZ 1842}

Pleuromya aff. mactroides Schloth.

\section{Est. I, fig. 5}

Material: 2 valvas direitas e um molde interno imperfeito duma valva direita.

Estado: a única charneira observável não se acha em estado satisfatório; as valvas não mostram os demais caracteres internos.

Medidas (tomadas sôbre o exemplar maior) :

$$
\text { N. }{ }^{\circ} \text { c } 29 \mathrm{~mm} \text { a } 21 \mathrm{~mm}
$$

Procedência: jazigo à direita da estrada de rodagem Rio Claro-Corumbataí, Ferraz.

Figuram na colecão duas valvas direitas e um molde interno muito imperfeito pertencentes a forma ainda não referida do triássico do Sul do Brasil.

O molde não of erece elemento algum, que mereça especial consideração. A valva mais completa mostra a charneira em estado não muito bom. Os demais caracteres internos são desconhecidos. Pode ser descrita como se segue.

Concha relativamente delgada, ineqüilatera, mactrácea, entumecida na região umbonal e deprimida para os bordos. Umbo saliente, submediano, prosógiro. Bordo inferior convexo. Extremidade anterior fortemente curva; extremidade posterior obliquamente truncada. Carena posterior muito fraca, curva. Superfície exierna apresentando estrias submarginais pouco pronunciadas. Linha da charneira sinuosa; no espécime em questão, parcialmente obstruida na região cardinal, não evidenciando por isso indício algum da denticão. Ligamento opistodético, apresentando-se bem distinta a ninf a ligamentar. 
EST. I

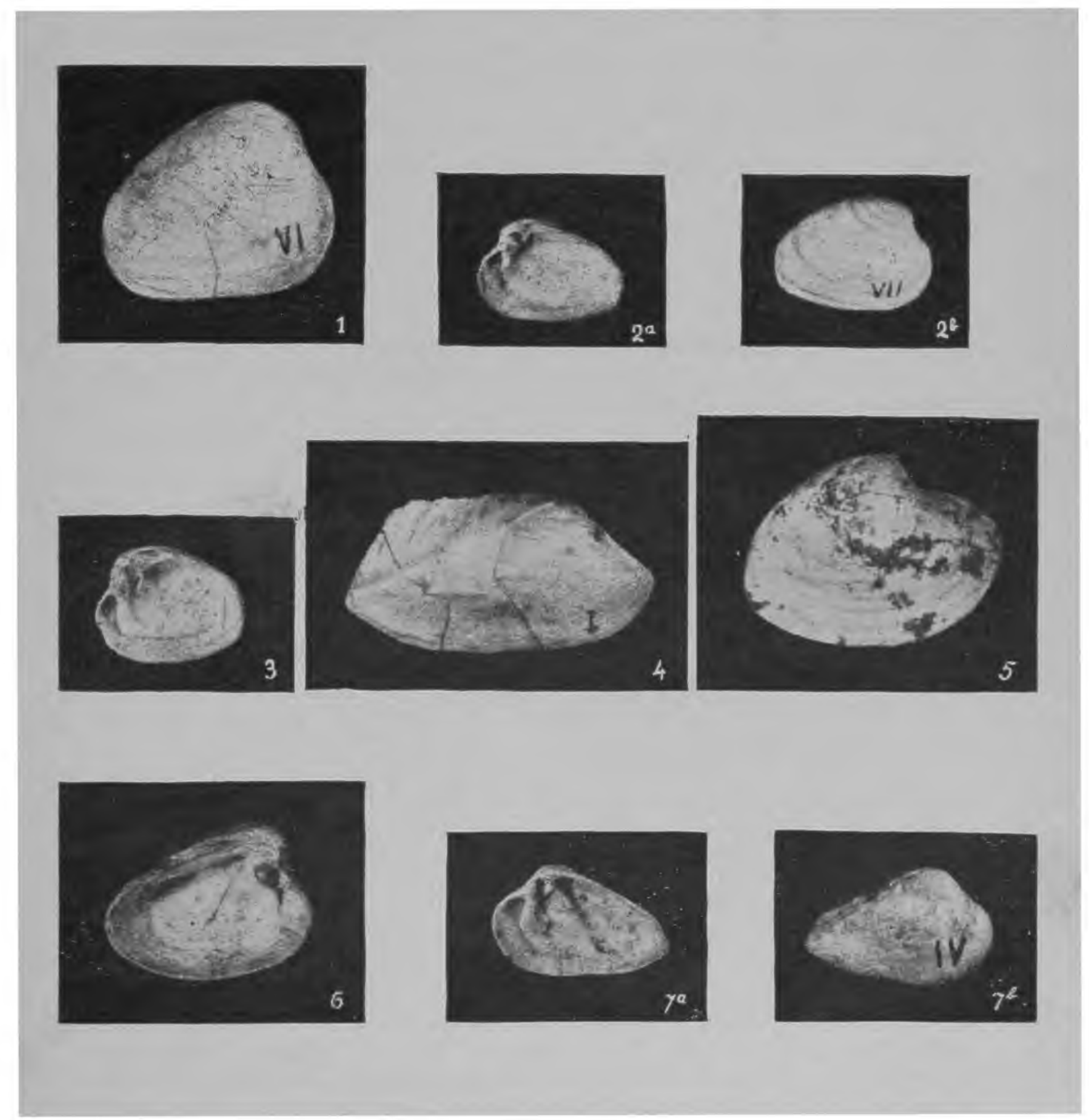




\section{Discussāo}

A soma dos caracteres, especialmente o aspecto da linha da charneira poderiam sugerir o gênero Ceromya Ağ., gênero êsse atribuido ao jurássico. Mas o mau estado da única charneira passivel de exame enfraquece desde logo qualquer apreciação mais segura a respeito. Tendo em consideração o aspecto externo, sinto-me mais inclinado a supor que se trata antes de uma forma aliada a Pleuromya mactroides Shloth. $(5, \mathrm{p} .47 \mathrm{t} .3 \mathrm{f} .1)$ do triássico germânico médio. Mas essa espécie é mais alongada e apresenta o umbo menos pronunciadamente prosógiro. Grosso modo lembra a forma referida por Holdhaus como Sanguinolites sp. (8, p.19 t.1 f.12), representada na coleção dêsse autor por um molde interno. Porém como foi figurada, não mostra o umbo tão pronunciadamente prosógiro e a carena posterior é muito mais forte e mais inclinada que a da presente concha.

Não fica afastada a possibilidade de se tratar duma forma nova, o que estudos posteriores eselarecerão à vista de material mais favoravel.

\section{B) Horizonte superior}

\section{PINZONELLOPIS GEN. N.}

Est. I, fig. 6,7a, 7b.

No seu primeiro trabalho sóbre o triássico do Sul do Brasil, Reed (13;13a) referiu conchas de Rio Claro (Marechal Malet, Paraná) ao gênero Pachycardia Hauer, dando uma forma como $P$. aff. rugosa Hauer $(13$, p. 40-41, t.1 f.1; 13a. p.11-12 t. f.1) e descrevendo outra com o nome de $P$. neotropica $(13$, p.44-45 t.1 f.3-3b; 13a, p.16-17 t. f.3-3b). A primeira não mostrou os caracteres externos; a charneira da segunda, de acôrdo com êsse autor, apresentaria, na valva esquerda, um dente cardinal forte e um ou dois dentes menores transversais e, na valva direita, dois ou três outros pouco menos pronunciados. Referiu ainda um dente lateral posterior obscuro, fraco, fino, estreito, alongado. A sua descrição repousou sôbre moldes internos e valvas imperfeitas. Fez observar, entretanto, que a espécie devido ao seu peculiar traçado da linha palial poderia possivelmente pertencer a um novo sub gênero ou mesmo gênero. Em 1929 o m'esmo autor descreveu conchas de Água Quente (Paraná) como $P$ rugosa Hauer var.nov. occidentalis $(14$, p.70 t.5 f 7-10). Referiu dessa vez à nova variedade os espécimes tidos anteriormente como $P$ aff. rugosa Hauer. Figurou a charneira das duas valvas, mas não fêz a respeito nenhuma referência descritiva no texto. No mesmo trab? p.70-72 t.5 f.2-6a) atribuiu espécimes de Água $Q$ 
4 e 10), Rio Claro e Terezina a $P$. neotropica, figurando-lhes identicamente a charneira das duas valvas. Afirmou, então, que apresentavam os caracteres préviamente descritos. Em relação a $\boldsymbol{P}$. rugosa var. occidentalis escreveu (ibidem, $\mathrm{p}$. 70) : "A única diferença da forma tipo consiste no bico que é um tanto mais obtuso e ligeiramente mais anterior. Há alguma variação na altura relativa, no comprimento de nossos espécimes e na carina mais aguda" Porém a charneira, como foi figurada, não corresponde à diagnose original de $P$. neotropica. A figura 4 parece mostrar nitidamente que a valva esquerda possue um único dente cardinal, ladeado por duas fossetas, a não ser que se considere como dentes laterais a ninfa ligamentar, posta aí em evidência, e aquilo que deve corresponder ao bordo anterior fraturado.

A charneira da valva esquerda figurada em 3 , sugere dois dentes cardinais divergentes, mas está em desacôrdo com as duas outras figuradas (ibidem, t.5 f.2a e 4). A charneira da valva esquerda de $P$. rugosa Hauer var. occidentalis figurada em 8 não mostra a dentição satisfatóriamente porque não foi, ao que se percebe, completamente desimpedida da matriz. Também nã̃o é muito satisfatória a representação da charneira da valva direita (ibidem, t.5 f 10).

Nos trabalhos ulteriores sôbre o triássico do Brasil o mesmo autor notificou a ocorrência de $P$. rugosa var. occidentalis e de $P$. neotropica em coleção organizada por von Huene nas proximidades de Camaquan (Rio Claro, S. Paulo) $(15$, p.485; 15a, p.32), bem como em outra coleção organizada pelo Serviço Geológico em Colonia Vieira, Cánoinhas, Estado de Santa Catarina $(16 ; 16 a$, p.15).

A minha coleção inclui um número elevado de ex'emplares referiveis à Pachycardia rugosa var. occidentalis Reed e bôa parte dos mesmos apresenta a charneira e d'emais caracteres internos esplendidamente conservados. Procedem da mesma jazida de Camaquan onde haviam sido coletados por von Huene (9) e da jazida de Corumbataí.

Não revelou o material nenhuma forma referivel com segurança a $P$. neotropica Reed.

A observação acurada dos caracteres morfológicos dos espécimes levaram-me a concluir que os mesmos não podem ser referidos ao gênero Pachycardia Hauer, gênero êsse que sem duvida recordam apenas pelo aspecto externo.

Pachycardia é um gênero do triássico alpino cuja charneira apresenta dois fortes dentes cardinais divergentes e um dente posterior longo em cada valva; vide por exemplo Waagen (18, p.6-15 t.25 f.1-7 e t.26 f 1-11) e Wöhrmann (19, p.187-189 t.6 f.8-14). Ora, nos espécimes por mim examinados, a charneira mostrou, invariávelmente, na valva direita, uma fosseta triangular e dois dentes cardinais e, na valva esquerda, um único dente cardinal forte, flanqueado 
por duas fossetas. Não encontrei vestigio de nenhum outro dente.

A charneira concorda muitíssimo mais com a que o próprio Reed descreveu para o seu gênero Pinzonella (15; 15a), diferindo principalmente, em que este outro gênero por via de regra apresenta um único dente cardinal triangular na valva direita.

Constituem pois, referidos exemplares uma forma aliada a Pinzonella, podendo ser proposto para os mesmos um novo gênero, que denomino Pinzonellopis, ficando assim em evidência a estreita ligação com Pinzonella.

\section{Diagnose genérica}

Concha ineqüilatera, francamente ineqüivalva, cordiforme ou subtriangular, deprimida, mostrando na parte mediana um sulco raso de direção obliqua; valva direita mais longa, mais baixa e menos entumecida. Umbo anterior, proeminente, prosógiro. Carena encurvada; truncatura posterior oblíqua. Superfície externa ornamentada com estrias subconcêntricas mais ou menos acentuadas. Linha da charneira sinuosa. Valva esquerda apresentando uma placa cardinal semicircular, localisada sob o ápice do umbo, com um único dente cardinal proeminente, ladeado por duas fossetas dentárias; placa cardinal da valva direita com uma única fosseta dentária, em contraposição, flanqueada por dois dentes cardinais distintos.

Concha integro-paliada, tendo o interior dividido submedianamente em duas lojas por uma crista oblíqua baixa. Posição das impressões musculares semelhante a de Pinzonella. Impressão do adutor anterior subtriangular, bem marcada; impressão do adutor posterior maior, mais leve.

Ligamento externo, opistodético.

Genótipo: Pinzonellopis occidentalis (Reed).

A espécie descrita por Reed como Pachycardia neotropica é referivel a êsse novo gên'ero.

\section{Pinzonellopis occidentalis (Reed)}

Est. I, figs. 6, 7a, 7b.

Pachycardia aff. rugosa Reed 1928 (13, p.40-41 t.1 f.1; 13a, p.11-12 t. f.1).

Pachycardia rugosa var. occidentalis Reed 1929 (14, p.70

\section{t.5 f.7-10).}

Material: mais de uma centena de exemplares.

Estado: muitos individuos se acham em bom estado de conservação; 14 dêles mostram satisfatóriamente os caracteres dentários. 


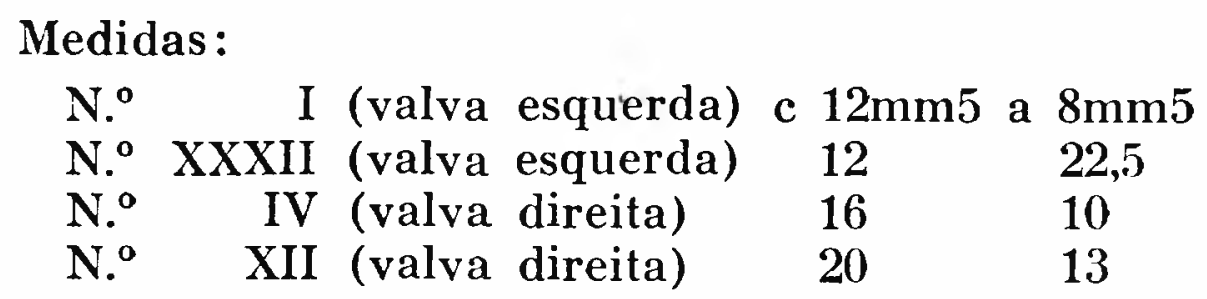

Procedência: os ns. I-LXX, procedem de Corumbatai; os restantes foram coletados em Camaquan.

A concha corresponde à referida em $1924(13 ; 13 a)$ por Reed como Pachycardia aff. rugosa Hauer e em 1929 (14) como Pachycardia rugosa var. nova occidentalis. No primeiro trabalho êsse autor descreveu-a externamente; no segundo, como já foi dito atráz, figurou-lhe a charneira, sem fazer no texto nenhuma referência descritiva a respeito. Assim reputo útil apresentar aquí uma descrição dos caracteres internos da mesma.

A charneira apresenta na valva esquerda uma placa cardinal semicircular com um único dente forte, obliquo, pro'eminente, subtriangular, de ápice obtuso cuja aresta mais aguda se liga, superiormente, ao bordo ântero-dorsal (bordo lunular) da valva. O espaço triangular compreendido entre êsse dente, o bordo lunular e a margem inferior da placa cardinal é ocupado por um alvéolo dentário profundo. Entre o dente cardinal e o bordo póstero-dorsal (ninfa ligamentar) há uma goteira relativamente profunda.

A charneira da valva direita apresenta uma fosseta triangular profunda, situada entre dois dentes cardinais fortes, subtriangulares, pouco proeminentes.

A concha é íntegro-paliada e tem o interior dividido submedianamente em duas lojas por uma crista oblíqua baixa. A posição das impressões musculares é semelhante a de Pinzonella. Impressão do adutor anterior forte, subtriangular. Impressão do adutor posterior maior, mais leve e pouco nítida. tura.

Devo acrescentar que a espécie é muito variável em alJACQUESIA, GEN. N.

Est. II, figs. 1, 2, 3.

No seu primeiro trabalho sôbre lamelibrânquios triássicos do Brasil Rieed (13; 13a) assinalou espécimes como Myophoria (Myophoriopis) aff. lineata (Münst.) e Myophoria (Myophoriopis) aff. carinata Bitt.

Em um segundo trabalho (14) mais amplo, registrou Myophoriopis martialis (sp. n., M. cf. kittli Bittner, $M$. cf. 
rosthorni Boué?, $M$. cf. richthofeni Stur, $M$. brasiliensis sp.n., $M$. aff. lineata Münster? e $M$. sp.

Referiu, dessa vez, a forma tida anteriormente como Myophoriopis aff. carinata à nova espécie $M$. brasiliensis (idem, p.72-74 t.5 f.1, 1a). Posteriormente, passou a atribuir a sua espécie martialis ao novo gênero Terraia de Cox $(16 ; 16 a)$, afirmando, então, que a mesma estava intimamente relacionada com $M$. brasiliensis.

Contando a minha coleção com uma bôa cópia de exemplares referiveis a $M$. brasiliensis Reed, foi-me possivel estudar a charneira e demais caracteres internos dessa espécie, até 'então desconhecidos. Os resultados do estudo, especialmente a observação dos caracteres dentários, levaram-me desde logo a retirá-la do gênero a que fôra atribuida. Com efeito, a simplicidade dentária notada nos espécimes não é própria de Myophoriopis Wöhrmann; vide, por exemplo, Bittner (1, p.108-116 t.13 f.1-17).

Parece-me, por outro lado, que os seus caracteres não se coadunam não só com os de Terraia Cox como com os de qualquer outro gênero conhecido dos terrenos secundários. Proponho para os mesmos um gênero novo com o nome de Jacquesia, em homenagem ao professor Dr. Luciano Jacques de Moraes, da Universidade de São Paulo.

Convém notar que a charneira dêste novo gênero lembra um tanto a de Ceromya Agassiz, do jurássico. Divergem porém os demais caracteres. Recorda também, ligeiramente, a de Burmesia? posteroradiata Cox do triássico do Vale do Jordão $(3, \mathrm{p} .85-6$ t.2 f.12a, b, c).

\section{Diagnose genérica}

Concha subtriangular, ineqüilatera e ligeiramente ineqüivalva. Umbo proeminente, subanterior, voltado para diante. Carena posterior forte. Extremidade anal truncada. Lúnula e vulva presentes. Ligamento externo opistodético. Superfície externa ornamentada com estrias subconcêntricas mais ou menos acentuadas.

Linha da charneira sinuosa. A valva direita mosira uma projeção do bordo lunular entumecida, simulando um dente cardinal alongado único. A valva esquerda mostra uma fosseta em contraposição, disposta anteriormente ao ápice do umbo. Impressão do adutor anterior pequena, piriforme, distinta; impressão do adutor posterior maior, pouco marcada. Linha palial simples.

Genótipo: Jacquesia brasiliensis (Reed.).

Possivelmente as demais formas atribuidas por Reed ao gênero Myophoriopis deverão ser referidas a êste novo gênero, ou eventualmente, ao gênero Terraia Cox. 


\section{Jacquesia brasiliensis (Reed)}

Est. II, figs. 1, 2, 3,.

Myophoriopis aff. lineata Reed 1928 (13, p.43-44 t.1 f.2; 13a, p.14-15 t.f.2).

Myophoriopis aff. carinata Reed 1928 (13, p.44 t.1 f.6, $6 a-b ; 15 a ; p .16$ t. f.6,6a-b). f.1,1a).

Myophoriopis brasiliensis Reed 1929 (14, p.72-74 t.5 f.6,6a).

Terraia martialis (Reed) $1935 \quad(16 ; 16 a$, p.13-14 t.1

Material: vários espécimes e alguns moldes internos.

Estado: grande parte dos espécimes se acham em bom estado de conservação; oito dêles permitiram a tomada de medidas; os individuos ns. I e X mostram respectivamente, os caracteres internos das valvas esquerda e direita; a charneira pode ser observada em vários exemplares.

Medidas:

$\begin{array}{lrlll}\text { N. } & \text { I (valva esquerda) } & \text { c } & 30 \mathrm{~mm} 5 & \text { a } 20 \mathrm{~mm} 5 \\ \text { N.o } & \text { VII (valva esquerda) } & 34 & 24,5 \\ \text { N.o } & \text { IV (valva esquerda) } & 37,5 & 27 \\ \text { N.o } & \text { VIII (valva esquerda) } & 41 & 28,5 \\ \text { N.o } & \text { II (valva direita) } & 34 & 21,5 \\ \mathrm{~N}^{\circ} & \text { III (valva direita) } & 36,5 & 25 \\ \mathrm{~N}^{\circ} & \text { V (valva direita) } & 37,5 & 27 \\ \mathrm{~N}^{\circ} & \text { VI (valva direita) } & 40 & 25,5\end{array}$

Procedência: os de ns. I-XX procedem de Corumbatai; os demais foram coletados em Camaquan.

\section{Descrição}

A diagnose original desta espécie repousa sôbre um molde interno bem conservado duma valva direita. R'efirirei aquí, tão sómente, em base dos meus exemplares, os caracteres que foram omitidos na mesma.

A concha é ornamentada com estrias subconcêntricas mais ou menos marcadas. A valva esquerda é mais bojuda e possui o bordo ventral pronunciadamente convexo.

A linha da charneira é sinuosa. A valva direita mostra uma projeção espêssa e entumecida do bordo lunular, à guisa dum dente cardinal único alongado. Um canal estreito corre entre a mencionada projeção e o umbo. A charneira da valva esquerda mostra uma fosseta em contraposição, dis- 
posta anteriormente ao ápice do umbo. São sobremodo evidentes as ninfas ligamentares.

A concha é um tanto variável em altura como demonstram as medidas. Nos exemplares estudados a percentagem da altura, tomada sôbre o comprimento, varia de 67 a $72 \%$ para a valva esquerda, e de 63 a $68 \%$ para a valva direita. Observação: - No seu primeiro trabalho sôbre o triássico do Brasil Reed (13) comparou alguns moldes internos procedentes de Malet, Estado do Paraná, com Myophoriopis lineata Münster e $M$. carinata Bittner. Mas, pela descrição e pelas figuras apresentadas, correspondem tão bem aos meus exemplares de $J$ brasiliensis que não tenho nenhuma dúvida em referi-los como pertencentes a esta éspécie. $O$ mesmo pode ser dito em relação à valva direita de Canoinha, Santa Catarina, mencionada como Terraia martialis (Reed) $(16 ; 16 a)$.

\section{GENERO PSEUDOCORBULA PHILIPPI 1898}

Várias conchas do triássico sul-americano foram atribuidas por Reed $(14 ; 16 ; 16 a)$ e Cox $(4)$ ao gênero Pseudocorbula de Philippi. A verdade porém é que não há muita concordância entre os caracteres das charneiras observadas nos espécimes sul-americanos e os mencionados na diagnose original dêsse gênero $(12$, p.168-173 t.5 f.5, 7,8).

\section{Pseudocorbula camaquensis sp. n.}

Est. II, figs. $4 \mathrm{a}, 4 \mathrm{~b}$ e 5 .

Material: 5 valvas esquerdas e 4 direitas.

Estado: com exceção duma valva esquerda (individuo n. I) quase perfeita, as demais não estão em muito bom estado. Os indivíduos I e IV são os que mostram melhor os caracteres internos.

Medidas (tomadas sôbre os individuos mais completos) :

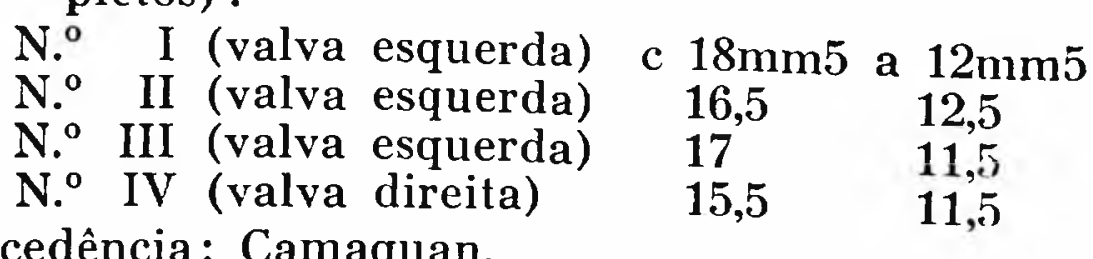

Procedência: Camaquan.

Descrição

Concha subelítica, ineqüilatera, moderadamente abaulada na parte anterior, comprimida posteriormente. Umbo re- 
duzido, subanterior. Extremidacie anterior arredondacia. Extremidade posterior estreita, procminente, verticalmente truncada (subestrangulada em dois individuos). Carcna posterior, fraca, indo do umbo ao extremo inferior da truncatura posterior. A linha da carena, do bordo vulvar e a truncatura posterior delimitam uma pequena área triangular estreita, ligeiramente deprimida, Lúnula e vulva presentes.

Valva esquerda mais alongada, mostrando na linha da charneira uma fosseta triangular, cujo ápice quase atinge a parte mais elevada do umbo. Não há indício de um dente posterior reduzido como em $P$. anceps. A área cardinal posterior à fosseta é achatada; a anterior é saliente, em aresta, prolongando-se através da aba saliente do bordo lunular. Valva direita apresentando um único dente cardinal forte, proeminentc.

Superfície externa, ornamentada com linhas concêntricas pouco salientes.

A impressão do adutor é bem marcada, piriforme, maior que a do adutor posterior. Localisa-se imediatamente sob o bordo lunular, próxima do bordo anterior da valva e é encimada por uma pequena impressão triangular distinta do músculo pedial. A impressão do adutor posterior é triangular, situa-se sob o bordo vulvar, um tanto afastada do extremo posterior. Faltam elementos para se opinar seguramente sobre a linha palial.

\section{Discussão}

Os caracteres dentários desta concha assemelham-se aus do gênero Terraia Cox (4). Pelo aspecto externo recorda Myophoria (Heminajas) holdhausi Reed (14, p.26-30 t.1 f.1-5). A soma dos seus caracteres, entretanto, aproximamna muito mais de certas espécies do triássico sul-americano referidas ao gênero Pseudocorbula Philippi. Avisinha-se um tanto de $P$. subtriangularis Reed $(16 ; 16 \mathrm{a}, \mathrm{p} .12$ t.1 f.4), cuja diagnose repousa sobre uma única valva esquerda incompleta, de tamanho menor e que não mostrava os caracteres internos. Porém a cauda mais alongada e mais estreita é um traço caracteristico que, aliado à ornamentação fraca a rlistingue bem, não só dessa espécie como das demais do triássico sul-americano atribuidas ao gênero Pseudocorbula. A nova espécie leva o nome do lugar de procedência.

Pseudocorbula triangularis sp. n.

Est. II, figs. 6a, 6b.

Material: 1 valva esquerda e uma direita.

Estado: o individuo n. I (valva esquerda) é incompleto e não mostra os caracteres internos; 0 
EST. II
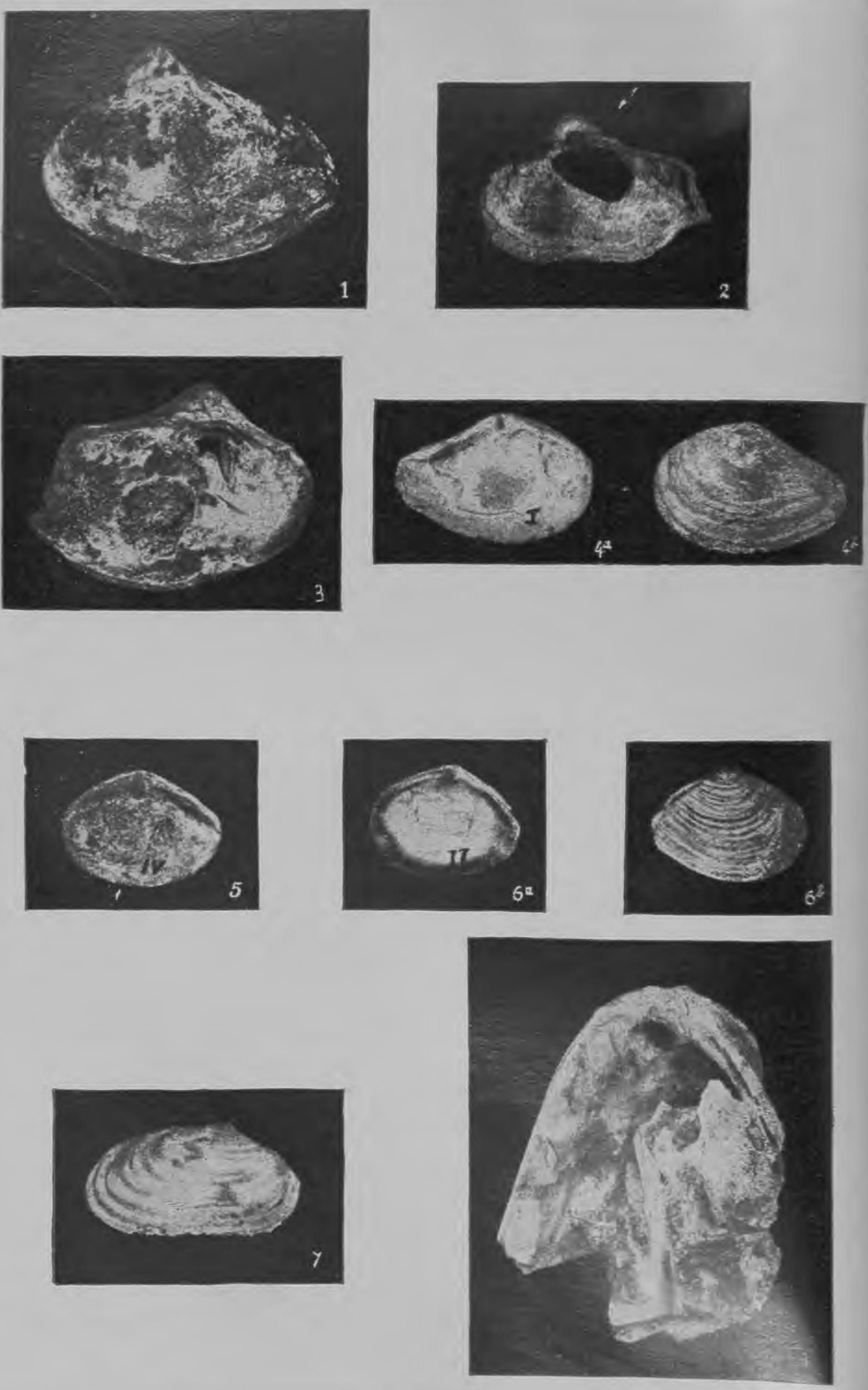
individuo n. II, é completo e mostra satisfatóriamente os caracteres internos.

Medidas:

N..$^{\circ}$ II (valva direita) c $14 \mathrm{~mm} 5$ a $11 \mathrm{~mm}$

Procedência: Corumbatai, Rio Claro.

\section{Descrição}

Concha subtriangular, subeqüilatera, moderadamente entumecida anteriormente. Umbo proeminente, submediano. Extremidade anterior arredondada; extremidade posterior oblíquamente truncada. Carena posterior arqueada, de convexidade voltada para fóra. Lúnula e vulva estreitas. Bordo inferior sinuoso, convexo nos dois tercos anteriores e côncavo no último terco posterior. Linha da carena muito próxima do bordo vulvar. Ornamentação externa constituida por 23 - 25 costelas salientes.

Valva direita apresentando um único dente cardinal forte, proeminente, triangular, obliquo. Impressões musculares bem pronunciadas. Impressão do adutor anterior piriforme, encimada por uma pequena impressão triangular do musculo pedial. Impressão do adutor posterior subtriangular. Linha palial sinuosa posteriormente. Sob o bordo lunular há uma saliência submarginal fraca, interrompida antes do dente cardinal, à guisa dum dente lateral anterior. Desconhecem-se os caracteres internos da valva esquerda.

\section{Discussão}

A concha pelo aspecto externo aproxima-se de $P$. subtriangularis Reed $(16 ; 16 \mathrm{a}$. p.12 t.1 f.4), mas os seus bordos vulvar e lunular unem-se ao ápice do umbo em ângulo mais agudo (cêrca de $125^{\circ}$ ) e é mais curta e mais alta que essa espécie. Não encontrei maior semelhança entre a mesma 'e as demais Pseudocorbula conhecidas do triássico sulamericano.

Penso poder referir à presente espécie a concha reconhecida por Reed (1928) como Anodontophora aff. trapezoidalis Mansuy $(13$, p.41-42 t.1 f 7-8; 13a. p.12-13 t. f.7-8), pelo menos a figurada em 7 .

\section{Pseudocorbula anceps Reed}

Material: 2 valvas esquerdas e 2 direitas.

Estado: o indivíduo n. II mostra a charneira e os demais caracteres internos da valva esquerda; o indivíduo n. III mostra satisfatóriamente a charneira da valva direita, mas é incompleto. 
Medidas :

$\begin{array}{llll}\text { N. } & \text { I (valva esquerda) } & \text { c } 17 \mathrm{~mm} \text { a } & 13 \mathrm{~mm} 5 \\ \mathrm{~N}^{\circ} \text { II (valva esquerda) } & 13 & 10,5 \\ \mathrm{~N}^{\circ} \text { IV } & \text { (valva direita) } & 14,5 & 11,5\end{array}$

Procedência: os ns. I, II e III procedem de Corumbataí; e o n. IV procede de Camaquan.

Embora os exemplares em questão apresentem maior número de costelas na ornamentação externa (17-23), nos pormenores da dentição, traçado subelítico e demais caracteres, concordam com a espécie de Rio Claro, Canoinhas (Estado de Santa Catarina) que Reed descreveu como $P$. anceps $(16 ; 16 \mathrm{a}, \mathrm{p} .10-12$ t.1 f.1-3a)

Não tendo sido descritas ainda as impressões internas dessa espécie, passo a considerá-la em base do presente material. A impressão do adutor anterior é bem marcada, piriforme e encimada por uma diminuta impressão do músculo pedial; a impressão do adutor posterior é igualmente bem marcada e subtriangular. A posição das impressões musculares é semelhante $\dot{a}$ de $P$. camaquensis ou $P$. triangularis acima descritas. A linha palial é sinusada posteriormente.

\section{Pseudocorbula subtriangularis Reed}

Material: 1 valva direita e 1 esquerda.

Estado: nenhuma das duas valvas mostra os caracteres internos; o indivíduo $\mathrm{n}$. II é o único completo.

Medidas :

N. ${ }^{\circ}$ II (valva direita) c $14 \mathrm{~mm}$ a $9 \mathrm{~mm} 5$

Procedência: o individuo n. I procede de Corumbataí; o individio n. II procede de Camaquan.

O exemplar $n$. I apresenta 17-18 costelas; o n. II apresenta a ornamentação um tanto obstruida com cêrca de 14 costelas. Mas o traçado subtriangular os aproxima fortemente de $P$. subtriangularis Reed, conhecida de Canoinhas, Estado de Santa Catarina (16; 16a, p.12 t.1 f.4).

\section{GENERO ANOPLOPHORA (ANODONTOPHORA)}

SANDBERGER 1862

Anoplophora intricans sp. $\mathrm{n}$.

Est. II, fig. 7.

Material: 1 valva direita.

Estado: a valva está quase completa, mas não mostra os caracteres internos. 
Medidas:

\author{
c $20 \mathrm{~mm}$ a $10 \mathrm{~mm} 5$ \\ Procedência: Corumbataí.
}

\title{
Discussâo
}

Concha elitica, alongada, ineqüilatera, deprimida lateralmente. Umbo subanterior, pouco proeminente. Superfície externa ornamentada com estrias concêntricas pouco pronunciadas. Extremidade posterior arredondada.

$O$ ângulo dorso-anterior bem como parte da margem ventral da valva estão obstruidos. dético.

Lúnula e vulva indistintas. Ligamento externo, opisto-

\section{Descriçâo}

Reed atribuiu ao gênero Anodontophora várias conchas do triássico do Sul do Brasil, referindo-as como $A$. aff. trapezoidalis Mansuy $(13 ; 13 a) A$. cf. lettica Qu'enstedt, $A$. aff. munsteri Wissmann, A. cf. recta Gumbel (14) e A. morata sp. n. $(16 ; 16 a)$. Notificou também a presenca de espécies indetermináveis de Anodontophora na coleçã̉o organizada por von Huene nas proximidades de Camaquan, S. Paulo $(15 ; 15 a)$.

Os caracteres externos da presente forma parecem concordar com os do gênero Anoplophora (Anodontophora) Sandberger do triássico, mas não me parece possivel identificá-la com nenhuma das acima referidas nem com as referidas por Jaworski como Anodontophora cf. edmondiformis Trech (Cerro do Pasco, Perú) (10, p.121-122) e Anodontophora (?) elongata Moore (Huairas) (idem, p.122-124 t.4 f.8). O seu traçado lembra menos $A$. lettica Quenstedt, como figurada por Philippi $(12, t .6$ f .5$)$. que a mencionada por Reed como $A$. ef. leltica (14, p.54 t.3 f.18-19). Penso poder referi-la como uma espécie nova.

\section{GENERO MYOCONCHA SOWERBY 1824}

Myoconcha sp.

Est. II, fig. 8

Alguns exemplares fragmentários coletados em Corumbataí e Camaquan, embora não mostrem satisfatóriamente os caracteres internos, podem, possivelmente ser referidos ao gênero Myoconcha de Sowerby. Qualquer tentativa de determinação específica, entretanto, seria descabida no caso. 
Os fragmentos devem pertencer a uma espécie pelo menos duas vezes superior em tamanho à $M$. crassa Sowerby (cêrca de $35 \mathrm{~mm}$ ). São consistentes e apresentam umbo quase nada proeminente, subterminal, voltado para baixo, de cujo ápice parte, em direção ao bordo ventral, uma carena forte, encurvada 'e saliente. A área compreendida entre a linha da carena e o bordo dorsal é escavada e relativamente larga. Mostra nitidamente uma goteira alongada, paralela ao bordo dorsal e destinada a receber o ligamento. A impressão do adutor anterior é profunda e subcircular.

O mau estado de conservação da charneira impossibilita a apreciação dos caracteres dentários.

Alguns moldes fragmentários de p'equenas dimensões procedentes de Serrinha foram referidos por Reed como Myoconcha aff. goldfussi Dunker (14, p.60-62 t.4 f.16). Não há, porém, têrmo de comparação entre os mesmos e os exemplares ora em questão.

O gênero Myoconcha Sow, teria vivido desde o carbonífero até o cretáceo $(20, \mathrm{p} .462)$; para Fischer, entretanto, as pretensas Myoconcha dos terrenos paleozóicos são na verdade Modiolopsis (7, p.1014).

\section{CON C L U S Õ ES}

Grosso modo a malacofauna triássica da série Corumbatai de São Paulo é identica à das camadas Terezina e Serrinha do Paraná, bem como às de Santa Catarina, Uruguai e Paraguai da posição estratigráfica correspondente.

Entretanto as associações faunísticas dos dois horizontes estudados não correspondem exatamente às conhecidas das camadas de Serrinha e Terezina (horizontes A e B de Reed) do Estado do Paraná (14). Assim na lista fornecida por êsse autor para o horizonte B (idem, p.80-82) figuram, entre outras espécies, Pachycardia rugosa Hauer var. occidentalis Reed, Plesiocyprinella carinata Hold. e Pleurophorus cf. elongatus Moore?. Mas Pachycardia rugosa Hauer var. occidentalis Reed, ou antes Pinzonellopis occidentalis (Reed), foi encontrada por mim unícamente nos jazigos do horizonte superior de marga creme, onde é muito abundante, enquanto as duas outras formas foram coletadas no horizonte inferior. Neste mesmo horizonte encontrei a espécie Terraia altissima (Hold.) (= Isocyprina reducta Reed), referida ao horizonte $\mathrm{A}$.

As formas do triássico do Sul do Brasil referiveis a espécies européias são poucas e inseguras. No presente trabalho demonstrou-se ser inexata a atribuição de certas espécies ao gênero Pachycardia Hauer do triássico alpino, propondo-se para as mesmas o novo gênero Pinzonellopis. Outro gênero novo, Jacquesia, foi proposto para conchas ante- 
riormente referidas ao gênero Myophoriopis. Plesiocyprinella, Terraia, Ferrazia e Pinzonella são outros tantos gêneros peculiares ao triássico sul-americano. A associação mostra, portanto, um caráter próprio, que dificulta sobremodo a sua correlação mais segura com as faúnas isócronas européias. Não possue a riqueza de cefalópodos, nem as formas de dentadura complexa conhecidas dos sedimentos ocidentais mais profundos do mar andino (10). Não ha também noticia segura sobre a ocorrência de gasterópodos nessa malacofauna transgressiva. Foram encontrados com os Lamellibranchiata espécimes de Radiolaria (13; 13a) e Crinoidea (14) não determinadas especificamente. Moraes Rego refieriu a ocorrência em Guareí, Estado de S. Paulo, dum exemplar fragmentário do Scaphopoda por êle classificado como Dentalium florencei sp. n. (").

Discutindo as associações faunisticas das camadas Terezina e Serrinha, Estado do Paraná, Reed (14) referira que, tanto a presença dum fragmento de Clionites, como a de certas formas idênticas ou dificilmente separáveis de espécies características das camadas com Pachycardia do Sul da Europa, indicariam o têrmo superior do triássico (cárnico médio). Não deixou de mencionar o autor que as espécies de Isocyprina bem como de Thracia pristina Reed do horizonte A sugeririam o andar rético.

As conchas determinadas como Pachycardia por Reed entretanto não pertencem verdadeiramente a êsse gênero. Plesiocyprinella liga-se estreitamente ao gênero jurássico Plesiocyprina. Se fôr efetiva a ligação da concha aquí referida como Pleuromya aff. mactroides Schloth. àquela espécie germânica ficaria também sugerido o triássico médio. Parecem-me, portanto, que a argumentação maior em prol do triássico superior repousa quase exclusivamente na presença dêsse fragmento de cefalópodo tido como pertencente ao gênero Clionites, provavelmente ao subgênero Traskite Hyatt \& Smith.

Os resultados a que cheguei, no tocante à distribuicão dos espécimes por horizontes, não concordam também plenamente com os apresentados no trabalho de Reed para a mesma região $(15 ; 15 a)$.

Jacquesia brasiliensis foi atribuida ao horizonte inferior, conquanto eu só a tenha encontrado no horizonte superior. Possivelmente passou algum engano na etiquetagem dos exemplares enviados por von Huene. A menos que o material esteja muito alterado, distinguem-se fácilmente os espécimes do horizonte superior não só pela coloração creme clara que apresentam como pela litologia da matriz.

(*) Rego, L. F de Moraes. - Contribuição ao estudo das ca. madas superiores da Série Passa Dois. An.Ac.Br.Ci., v 8, 1936, n. 1, p. 41-52. 


\section{I T E R A T U R A}

(1) - BITTNER, A. - Lamellibranchiaten der alpinen Trias. I Revision der Lamellibranchiaten von St. Cassian. Abh. K. K. Geol. Reischsanst. v. 18/1, 1895 .

(2) - BEDER, ROBERTO - Sobre un hallazgo de fóssiles permicos en Villarica (Republica del Paraguay) - Bol. Ac. Nac. Ci., Cordoba v. 27, 1923, p. 0-12.

(3) - COX, LESLIE R. - A Triassic Fauna from the Jordan Valley - An. Mag. Nat. Hist., ser 9, v. 14, 1924, p. $52-96$, t. 2 .

(4) - - Triassic Lamellibranchia from Uruguay An. Mag. Nat. Hist., ser 10, v 13, 1934, p. 26473, t. 10 .

(4a) - - I.amelibranquios triássicos do Uruguai. (trad.) - Div. Geol. Min., bol. n. 107, Rio de Janeiro 1942 (1943)

(5) - DIENER, C. - Leitfossilien - IV Leitfossilien der Trias. - Berlin, 1925.

(6) - DU TOIT, A. L. - A geological comparison of South America with South Africa. - Carn. Inst. Washington. Publ. 381, 1927

(7) - FISCHER, PAUL - Manuel de Conchyologie et de Paléontologie Conchyliologique. Paris (F. Savy), 1887

(8) - HOLDHAUS, KARL - Sobre alguns lamellibranchios fosseis do sul do Brasil. - Serv. Geol. Min. Brasil. Monog. II, Rio de Janeiro, 1918, $2 \mathrm{t}$.

(9) - HUENE, FRIEDRICH VON - Aphorismen über die Stratigraphie des brasilianischen Staates São Paulo. Ctbl. f. Min, etc. - Abh. B. 1928, p. 524-31.

(10) - JAWORSKI, E. -- Die marine Trias in Südamerika. - N. Jb. f. Min., etc., 47, B. B., 1923, p. 93-200, t. 4-6. 4 textf.

(11) - MOORE, CH. - Australian Mesozoic Geology and Palaeontology On the Zones of the Lower lias and the Avicula contorta Zone. - Quart. J. Geol. Soc. I.ondon, $v$ 17, 1861, p. 483-516.

(12) - PHILIPPI, E. - Die Fauna unteren Trigonodusdolomits von Hunherfeld bei Schwieberdinger und des sogenannten "Cannstatter Kreide-Mergels". Jahresch. Ver f. vater. Naturk. Würtemberg, 1899, p. 145-227, t. 4.9.

(13) - REED, F. R. COWPER - Triassic fossils from Brazil An. Mag. Nat. Hist., ser 2, v 10, 1928, p. 39-48.

(13a) - - Fosseis triássicos do Brasil (Trad.). - Div. Geol. Min., bol. n. 107, Rio de Janeiro 1942 (1943),
p. 10-12, 1 t.

(14) - - Faunas triássicas do Brasil. - Serv. Geol. Min. Brasil, Monog. IX, Rio de Janeiro, 1929, 97
p. 5 t.

(15) - - Some new triassic fossils from Brazil. t. 19 .

(15a) - Sobre alguns novos fósseis triássicos do Brasil (trad.) Div Geol. Min., bol. n. 107, Rio de Janeiro 1942 (1943), p. 25-34, $1 \mathrm{t}$. (16) - Some triassic lamellibranchs from Brazil and Paraguay. --
Geol. Magaz. v. 72, 1935, p. 33-42, t. 1 . 
(16a) - REED, F R. COWPER - Alguns lamelibrânquios triássicos do Brasil e do Paraguay (trad.). - Serv. Geol. Min. Brasil, bol. n. 98, Rio de Janeiro, 1940, 20 p. $1 \mathrm{t}$.

(17) - ROXO, MATHIAS OLIVEIRA - Secção de Paleontologia, in "Relatório Anual do Diretor, Ano de 1938" - Serv. Geol. Min. Brasil, Rio de Janeiro, 1939, p. 53-63

(18) - WAAGEN, L. - Die Lamellibranchiaten der Pachycardientuffe der Seiseralm. - Abh. K. K. Geol. Reischsanst. $18 / 2,1907$

(19) - WORHMANN, S. VON et KOKEN - Die Fauna der Raibler Schichten von Schernplateau. - Zeitsch. Deutsch. Greol. Ges. 44/2, 1892, p. 167-222, t. 6-16.

(20) - ZITTEL, KARL G. VON - Text-Book of Paleontology (edited by $\mathrm{Ch}$. Eastman) vol. I - Invertebrates. London (MacMillan and Co.), 1937.

\section{EXPLICAÇÃO DAS ESTAMPAS}

\section{ESTAMPA I}

Fig. 1 - Pinzonella trigona sp.n. Valva direita (n. VI), x 11/2 (aprox.). Chacara do sr. Göss, Ferraz.

$2 a, b$ - Idem. a) Vista interna da valva direita (n. VII), $\times 11 / 3$ (aprox.); b) Vista externa da mesma valva, x $11 / 3$ (aprox.). Jazigo à direita da estrada de rodagem Rio Claro-Corumbatai, Ferraz.

3 - Pinzonella similis Reed. Vista interna da valva direita (n. II), $x$ 1 $1 \frac{1}{2}$ (aprox.). Jazigo à direita da estrada de roda. gem Rio Claro-Corumbatai, Ferraz.

4 - Pleurophorus cf. elongatus Moore. Valva direita (n. I), x 11/2 (aprox.). Chácara do sr. Göss, Ferraz.

5 - Pleuromya aff. mactroides Schloth. Valva direita (n. I), x 11/7 (aprox.) Jazigo à direita da estrada de rodagem Rio Claro-Corumbatai, Ferraz.

6 - Pinzonellopis occidentalis (Reed) Vista interna da valva esquerda (n. XIII), x $1 \frac{1}{1} 2$ (aprox.) Corumbatai.

$7 a, b$ - Idem. a) Vista interna da valva direita (n. IV), x $11 / 3$ (aprox.); b) Vista externa da mesma valva, x $11 / 3$ (aprox.) Corumbataí.

\section{ESTAMPA II}

Fig. 1 - Jacquesia brasiliensis (Reed) Valva esquerda (n. IV), x 11/7 (aprox.) Corumbatai.

2 - Idem. Vista interna da valva direita (n. IX), x 11/6 (aprox.) Corumbatai.

3 - Idem. Vista interna da valva esquerda ( $n$. XI), x 11 1/6 (aprox.). Corumbatai.

$4 a, b$ - Pseudocorbula camaquensis sp.n. a) Vista interna da valva esquerda (n. I) , x 1 1/2 (aprox.); b) Vista externa da mesma valva, x 2 (aprox.) Corumbatai. 
5 - Idem. Vista interna da valva direita (n. IV), x 11/2 (aprox.) Corumbataí.

$6 a, b$ - Pseudocorbula triangularis sp.n. a) Vista interna da valva esquerda ( $\mathrm{n}$. II), $x 1^{1 / 2}$ (aprox.); b) Vista externa da mesma valva, $x 11 / 2$ (aprox.) Corumbataí.

7 - Anodontophora intricans sp.n. Valva direita, x 11/2 (aprox.) Corumbatai.

$S-$ Myoconcha sp. Vista interna (n. V), x $11 / 5$ (aprox.) Corumbatai.

As fotografias foram tomadas pelo sr. Giro Pastore, por especial deferência do Departamento de Zoologia da Secretaria da Agricultura do Estado de S. Paulo. 